\title{
Research on the micro-crack density of a chromium coating/steel substrate with and without laser pre-quenching treatment
}

\author{
Ban-Quan Yang ${ }^{1,2, a *}$, Guang-Nan Chen ${ }^{2, b}$ and Xue-Jun Chen ${ }^{3, c}$ \\ ${ }^{1}$ Division of Engineering Mechanics, Department of Mechanical Engineering, Academy of Armored \\ Force Engineering , No. 21, Du-Jia-Kan, Chang-Xin-Dian, Beijing 100072, P. R. China \\ ${ }^{2}$ Laboratory of surface modification, Institute of mechanics, Chinese Academy of Sciences, No. 15 \\ Bei-si-huan-xi Road, Beijing 100190, P. R. China \\ ${ }^{3}$ School of Applied Sciences, University of Science and Technology Beijing, No. 30 Xue-Yuan Road, \\ Beijing 100083, P. R. China \\ ayangbq1022@sina.com, bgnchen@imech.ac.cn, cchenxuejun@ustb.edu.cn
}

Keywords: Micro-crack density; $\mathrm{Cr}$ coating/laser pre-quenched steel substrate system; $\mathrm{Cr}$ coating/original steel substrate system.

\begin{abstract}
The initial micro-crack density of a chromium coating/steel substrate with and without laser pre-quenching treatment was investigated in this work. It was found the micro-crack density of $\mathrm{Cr}$ coating on the pre-quenched substrate surface was much lower than that of the Cr coating on the original substrate surface. Based on the results presented in this work and in the literature, the find presented in this work indicates the lower crack density of the chromium coating on the pre-quenched substrate may improve the mechanical properties of this material system, and it may be an important mechanism responsible for the prolonged lives of workpieces in practice.
\end{abstract}

\section{Introduction}

Electroplated chromium coatings have been widely used on engineering parts and composites such as piston rings, work rolls, aircraft landing gear and barrels of gun/cannon tubes etc. due to their high hardness, excellent wear and corrosion resistance, high melting point and low coefficient of friction [1-3]. However, under the severe service conditions such as thermal fatigue loading, gas erosion and severe stressing, cracking is usually caused at the coating or the substrate/chromium interface, which will result in the spallation of the chromium coatings from the substrate [4, 5]. The spallation of the coating from the substrate means the failure of the coating-substrate system to a certain extent. With more and more severe operating conditions, the single traditional chromium plating cannot meet the practical requests. In order to satisfy the practical requests, a novel technology of laser pre-quenching of steel substrate surface prior to plating the $\mathrm{Cr}$ coating has been presented $[6,7]$. This technology can greatly improve the bearing capability of the Cr coating/steel substrate system in practical conditions, as stated in Ref. [7, 8]. Some mechanisms responsible for the improvement have been reported, such as the hardness improvement of the steel substrate surface [8], the finer microstructure of the interface as well as the coating itself [7] and the decrease of the crack driving force in the hardened layer by residual compressive stress and yield strength improvement by the technology [9-11]. In this work, a comparative investigation on the initial micro-crack density of the $\mathrm{Cr}$ coating on the laser pre-quenched steel substrate surface and original steel substrate surface is investigated.

\section{Specimen preparation}

The substrate material was $30 \mathrm{CrNi} 2 \mathrm{MoV}$ (AISI 3034) steel (main chemical ingredients: 0.28C, $0.7 \mathrm{Cr}, 2.27 \mathrm{Ni}, 0.20 \mathrm{Mo}, 0.21 \mathrm{~V}$, all in wt. \%). The steel plate $99 \mathrm{~mm} \times 16.5 \mathrm{~mm} \times 5 \mathrm{~mm}$ was quenched using a continuous $\mathrm{CO}_{2}$ laser with beam power $600 \mathrm{~W}$, beam diameter $5 \mathrm{~mm}$ and beam scanning velocity $10 \mathrm{~mm} / \mathrm{s}$. The beam interval between two laser tracks is large enough so that the interaction between the neighboring tracks can be ignored. Their laser-quenched surfaces were mechanically 
ground and polished. The Cr coatings composed of low-contraction (LC) and high-contraction (HC) Cr were prepared by the commercial electroplating processing of the practical chromium-coated parts. The LC-Cr layer about $20 \mu \mathrm{m}$ thick was pre-deposited as an interlayer with the commercial plating bath of chromic acid $\left(250 \mathrm{gl}^{-1}\right)$ and sulfuric acid $\left(2.5 \mathrm{gl}^{-1}\right)$, at a temperature of $85{ }^{\circ} \mathrm{C}$ and a current density of $60 \mathrm{~A} / \mathrm{dm}^{2}$. The HC-Cr plate approximately $110 \mu \mathrm{m}$ thick was deposited at a lower bath temperature and a lower current density.

The dimension of the specimens is designed to be $6 \mathrm{~mm} \times 5 \mathrm{~mm} \times 5 \mathrm{~mm}$. The representative optical microscopes of the cross section of the two types of the specimens are shown in Fig.1 (a) and (b).
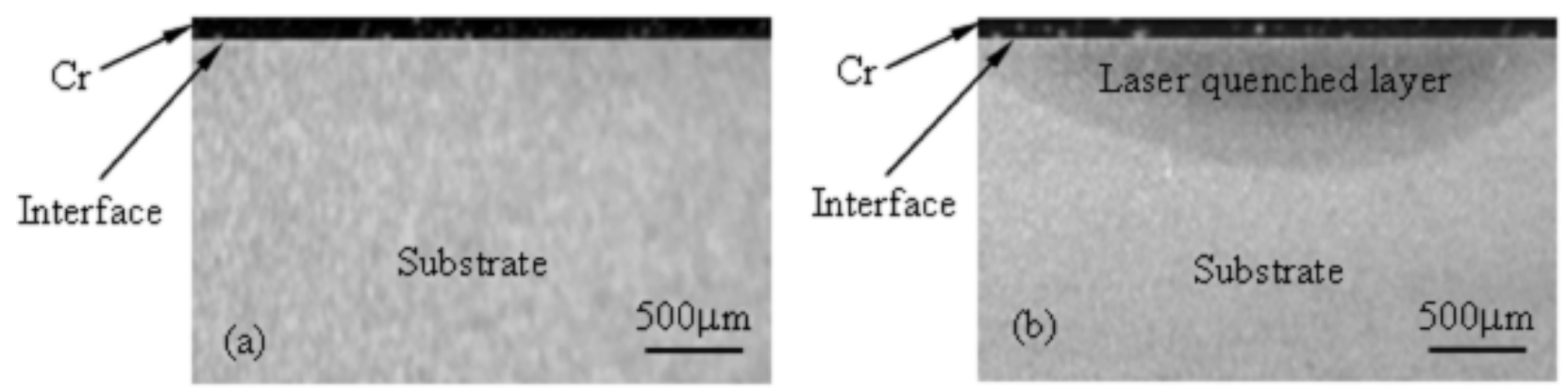

Fig. 1. The representative optical photo of the cross section of the two types of specimens: (a) Cr coating /original steel substrate; (b) Cr coating/laser pre-quenched steel substrate.

The initial representative optical microscopes of the cross-section of the two types of specimens are shown in Fig. 2(a) and (b).
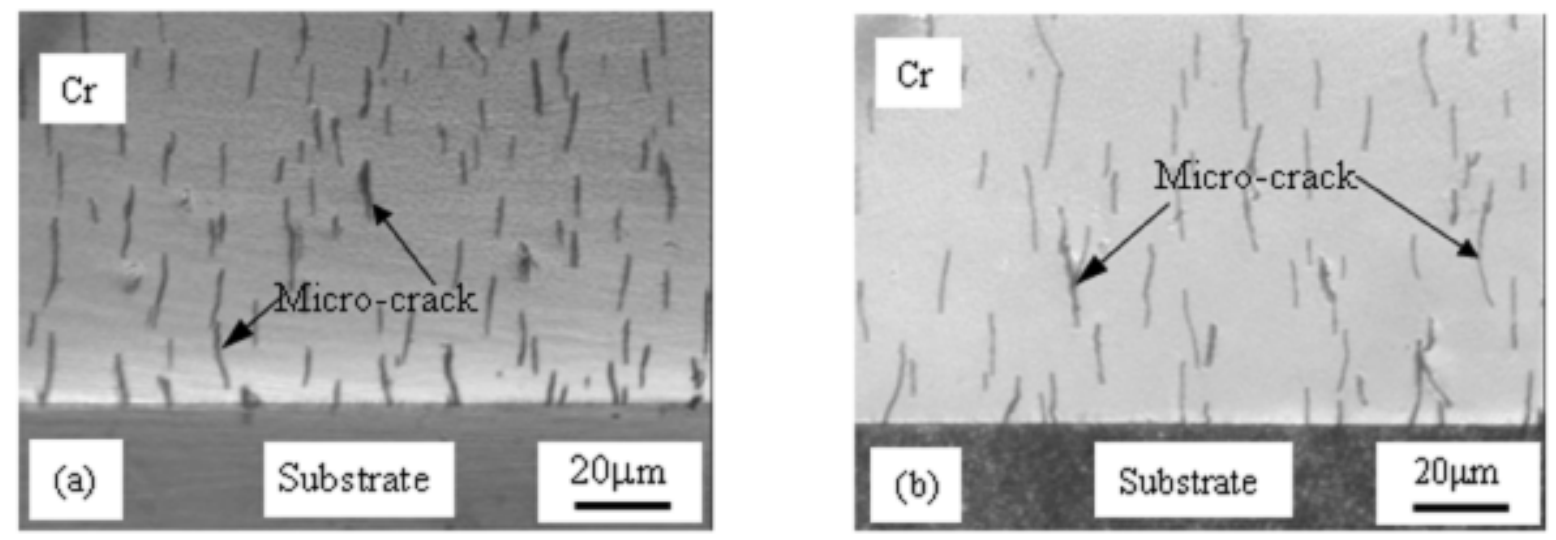

Fig. 2. The initial representative optical microscope of the cross-section of the two types of specimens: (a) $\mathrm{Cr}$ coating /original steel substrate; (b) Cr coating /laser pre-quenched steel substrate.

\section{Characterization of the crack density}

The crack density is often defined as the number of the cracks per unit distance [12-16]. It was found that the cracking of the coating initiated at critical strain, and then the number of the cracks of the coating per unit axial distance increased with the increase of the tensile strain [12-16]. At another critical strain, the crack density (the number of the cracks) of the coating became saturated, i.e. the number of cracks per unit axial distance became a constant after this critical strain [12-16]. Although the number of the cracks remained constant after the critical strain, the crack length or (and) width would increase with the increase of the tensile strain in order to accommodate the applied strain [12-16]. So, a more suitable parameter to characterize the crack density should be presented. In this work, a novel parameter involving the number of the cracks, the crack length and the crack width for characterization of the crack density of the coating is presented as 


$$
\varepsilon_{C}=\frac{\sum_{i=1}^{N} L_{C i} \times B_{C i}}{A} .
$$

Where $\varepsilon_{C}$ is the crack density of the coating, $A$ is the area of the coating, $N$ is the number of the cracks of the coating, $L_{C i}$ is the crack length, and $B_{C i}$ is the average crack width. All the parameters can be measured using the optical microscope.

\section{Results and discussions}

Using the optical microscope and the Eq. (1), the average crack density of the Cr coating on the pre-quenched substrate surface is $3.2 \times 10^{-2}$, and the average crack density of the Cr coating on the original substrate surface is $4.60 \times 10^{-2}$. The decrease rate of the crack density is significant, and it can be $30.4 \%$.

Since the technology of the laser pre-quenching of steel substrate surface prior to the chromium coating deposition can improve the load-bearing capacity of the material system $[7,8]$, the decrease of the crack density of $\mathrm{Cr}$ coating resulting from this technology may improve the mechanical properties of this material system, and it may be an important mechanism responsible for the prolonged lives of workpieces in practice

\section{Summary}

The micro-crack density of $\mathrm{Cr}$ coating deposited on the laser pre-quenched steel substrate surface is much lower than that of the $\mathrm{Cr}$ coating deposited on the original steel substrate surface. Based on the results presented in this work and in the literature, the lower crack density of the chromium coating on the pre-quenched steel substrate may improve the mechanical properties of this material system, and it may be an important mechanism responsible for the improvement of the load-bearing capacity of the chromium coating/steel substrate system in practice.

\section{Acknowledgements}

The authors gratefully acknowledge the financial support of the Postdoctoral Science Foundation of China (Grant No. 20100470149), the financial support of the National Natural Science Foundation of China (Grant No. 11002002, 10802007), the Specialized Research Fund for the Doctoral Program of Higher Education of Ministry of Education (Grant No. 20070008003).

\section{References}

[1] K.M.Yin and C.M.Wang: Surf. Coat. Technol. Vol. 114 (1999), p. 213.

[2] J.Simão and D.K. Aspinwall: J. Mater. Process. Technol. Vol. 92-93 (1999), p.218.

[3] L.Fedrizzi, S.Rossi, F.Bellei and F.Deflorian: Wear Vol. 253 (2002), p. 1173.

[4] B.Lawton: Wear Vol. 251 (2001), p. 827.

[5] S.Sopok, C.Richard and S.Dunn: Wear Vol. 258 (2005), p. 659. 
[6] W. Harald, S. Uvc, Germany Patent: DE19918794.

[7] G.N. Chen, G.X. Luo, K. Zhang, X.Y. Xu, H. Shen, H.M. Yan and D. Rao: Acta. Armament II(Suppl) Vol. 24 (2003), p. 6 (in Chinese).

[8] H.X. Li, G.N. Chen, G.X. Zhang, K. Zhang and G.X. Luo: Surf. Coat. Technol. Vol. 201 (2006)902.

[9] J. Grum and P. Žerovnik: Heat. Treat. Vol. 25 (1993), p. 32.

[10] B.Q. Yang, K. Zhang, G.N. Chen, G.X. Luo and J.H. Xiao: Acta. Mater. Vol. 55 (2007), p. 4349.

[11] B.Q. Yang, K. Zhang, G.N. Chen, G.X. Luo and J.H. Xiao: Surf. Coat. Technol. Vol. 201 (2006), p. 2208.

[12] B.Q. Yang, G.N. Chen, K. Zhang, G.X. Luo and J.H. Xiao: J. Mater. Process Technol. Vol. 209 (2009), p. 2180.

[13] B.Q. Yang, K. Zhang, G.N. Chen, G.X. Luo and J.H. Xiao: Surf. Eng. Vol. 24 (2008)332.

[14] D.C. Agrawal and R. Raj: Acta. Metall. Vol. 7 (1989), p. 1265.

[15] B.F. Chen, J. Hwang, G.P.Yu and J.H. Huang: Thin Solid Films Vol. 352 (1999), p.173.

[16] C.J. Xie and T. Wei: Acta. Mater. Vol. 53(2005), p. 477. 
High Performance Structures and Materials Engineering

10.4028/www.scientific.net/AMR.217-218

Research on the Micro-Crack Density of a Chromium Coating/Steel Substrate with and without Laser Pre-Quenching Treatment

10.4028/www.scientific.net/AMR.217-218.591

\section{DOI References}

[11] B.Q. Yang, K. Zhang, G.N. Chen, G.X. Luo and J.H. Xiao: Surf. Coat. Technol. Vol. 201 (2006), . 2208. doi:10.1016/j.surfcoat.2006.03.030

[12] B.Q. Yang, G.N. Chen, K. Zhang, G.X. Luo and J.H. Xiao: J. Mater. Process Technol. Vol. 209 2009), p. 2180.

doi:10.1016/j.jmatprotec.2008.05.018

[14] D.C. Agrawal and R. Raj: Acta. Metall. Vol. 7 (1989), p. 1265.

doi:10.1016/0001-6160(89)90088-6

[15] B.F. Chen, J. Hwang, G.P.Yu and J.H. Huang: Thin Solid Films Vol. 352 (1999), p.173.

doi:10.1016/S0040-6090(99)00342-9 